\title{
Commentary: Winning the race after lung surgery: The tortoise or the hare?
}

Twenty years ago, a study suggested that pneumonectomy can be safely performed as an outpatient procedure. ${ }^{1}$ The same group recommended 1-day admission after major lung resection in octogenarians. ${ }^{2}$ Needless to say, this has yet to permeate into routine practice. Lung surgery generally requires intubational anesthesia, intercostal incisions, and a variety of intrapleural, venous, urinary, and oxygen catheters. Patients are frequently elderly and have associated comorbidities. Despite this, and thanks to "fasttracking," the hospital length of stay (LOS) after lung surgery has decreased over time but continues to average about 6 days in the United States. ${ }^{3}$ Even the Society of Thoracic Surgery General Thoracic Surgery Database (STSGDB) has a median LOS of 5 days. ${ }^{4}$

The question of when a patient can be discharged is multifaceted, but undeniably, medical readiness and chesttube removal are just 2 of the many factors. Others include surgeon preference, intraoperative findings, institutional features, social demographics, and the soft but powerful influence of the patient's expectations. Naturally, the undisputed advantage of early discharge is hospital cost savings. ${ }^{5}$ Otherwise, it is unlikely that hospital-acquired conditions occur more frequently in any of the first few days of the postoperative period.

Linden and colleagues ${ }^{6}$ analyzed the STSGDB from 2012 to 2017 for postoperative day 1 discharges (POD1DCs) after anatomic resections for lung cancer. Of 46,325 patients only $1821(3.9 \%)$ were discharged on POD1 and 11 of the $278(3.9 \%)$ participating sites had more than $20 \%$ POD1-DCs. Interestingly, 5\% of POD1-DCs were sent home with chest tubes. Not surprisingly, POD1-DCs tended to be younger, healthier, and less likely to have had a lobectomy. The study concludes that POD1-DCs after anatomic lung resection are rare but can be done safely, as evidenced by the low rates of complications and readmission.

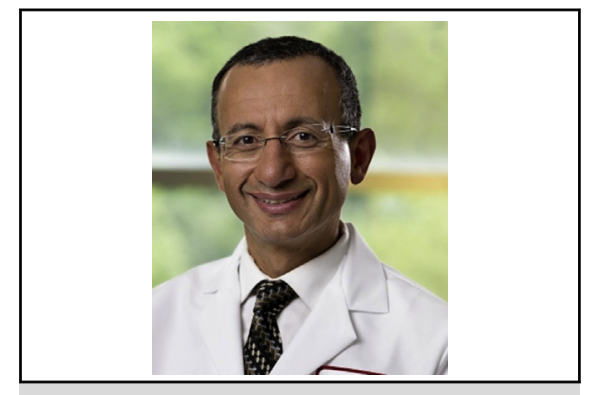

Abbas E. Abbas, MD, MS, FACS

Central Message

Next-day discharge after lung surgery requires careful planning to avoid complications and readmissions. Anatomic lung resection should not be considered a minor procedure.

See Article page 667.

This information is interesting. However, despite the STSGDB being arguably our most comprehensive thoracic registry, it does not share specific surgeon or center determinants and lacks precise information on social conditions, intention behind clinical decisions, and severity of complications. Postdischarge complications may not be well identified or documented.

As the cost of health care escalates, surgeons must be good stewards of hospital resources by avoiding unnecessary devices, medications, investigations, and lengthy LOS. However, this must never encroach on the patient's best interests. Certainly, the best way to cut costs is by improving outcomes. In fact, most of the morbidities after lung surgery, such as arrhythmia, pneumonia, myocardial ischemia, pleural effusion, and death, occur later than POD1. ${ }^{7}$ These may be uncommon but will occur. Indeed, a recent study of the Premier database revealed increased readmissions for LOS less than 5 days. ${ }^{8}$

Although POD1-DC after this operation may be feasible, we must avoid the perception that lung resection is a minor outpatient procedure. Discharge planning must include caution on complications and when to seek medical attention. Special attention must be given to patients with advanced age, comorbidities, or unfavorable living conditions. Surgeons should actively seek reasons to deny early discharge, permitting it only when none exists. Such is how the methodic tortoise always bests the overzealous hare. 


\section{References}

1. Tovar EA. Minimally invasive approach for pneumonectomy culminating in an outpatient procedure. Chest. 1998;114:1454-8.

2. Tovar EA. One-day admission for major lung resections in septuagenarians and octogenarians: a comparative study with a younger cohort. Eur J Cardiothorac Surg. 2001;20:449-53; discussion 453-4.

3. Giambrone GP, Smith MC, Wu X, Gaber-Baylis LK, Bhat AU, Zabih R, et al. Variability in length of stay after uncomplicated pulmonary lobectomy: is length of stay a quality metric or a patient metric? Eur J Cardiothorac Surg. 2016;49: e65-71.

4. Tong BC, Kim S, Kosinski A, Onaitis MW, Boffa DJ, Habib RH, et al. Penetration, completeness, and representativeness of the society of thoracic sur- geons general thoracic surgery database for lobectomy. Ann Thorac Surg. 2019;107:897-902.

5. Paci P, Madani A, Lee L, Mata J, Mulder DS, Spicer J, et al. Economic impact of an enhanced recovery pathway for lung resection. Ann Thorac Surg. 2017;104:950-7.

6. Linden PA, Perry Y, Worrell S, Wallace A, Argote-Greene L, Ho VP, et al. Postoperative day 1 discharge after anatomic lung resection: a Society of Thoracic Surgeons database analysis. J Thorac Cardiovasc Surg. 2020;159:667-78.e2.

7. Ferretti G, Brichon P, Jankowski A, Coulomb M. Postoperative complications after thoracic surgery. J Radiol. 2009;90:1001-12.

8. Freeman RK, Dilts JR, Ascioti AJ, Dake M, Mahidhara RS. A comparison of length of stay, readmission rate, and facility reimbursement after lobectomy of the lung. Ann Thorac Surg. 2013;96:1740-5; discussion 1745-6. 